\title{
Acute Anterior Uveitis in patients with ankylosing spondylitis in northeast of Iran
}

\author{
Mohammadhassan Jokar ${ }^{1,2 *}$, Mina Jokar ${ }^{3}$ \\ ${ }^{1}$ Golestan Rheumatology Research Center, Golestan University of Medical Sciences, Gorgan, Iran. ${ }^{2}$ Faculty of \\ Medicine, Mashhad University of Medical Sciences, Mashhad, Iran. ${ }^{3}$ Faculty of Medicine, Islamic Azad University, \\ Mashhad Branch, Mashhad, Iran
}

\begin{abstract}
Ankylosing spondylitis (AS) is a chronic inflammatory rheumatic disorder with variable clinical manifestations. Acute anterior uveitis is the most common extra-articular manifestation of ankylosing spondylitis. This study assessed the prevalence of uveitis in patients with ankylosing spondylitis in Mashhad, Iran.

In this retrospective study, the medical records of patients diagnosed with AS between January $1^{\text {st }}, 2007$ and December $31^{\text {st }}, 2017$ in a rheumatology clinic in Mashhad, Iran were reviewed. Diagnoses of ankylosing spondylitis were made based on the modified New York criteria.

The records of 317 patients were reviewed ( $81.4 \%$ male, $18.6 \%$ female, with a male to female ratio of $4.3: 1)$. The mean age at onset of AS was $27.01 \pm 8.63$ years (minimum 12 years, maximum 55 years). The mean age at diagnosis of AS was $30.72 \pm 9.44$ years. The mean age at diagnosis of uveitis was $32.40 \pm 10.49$ years. The mean follow-up period of patients was $6.19 \pm 5.51$ years. HLA-B27 was positive in $77 \%$ of patients. About $14 \%$ of patients had uveitis in the mean follow-up period of $6.19 \pm 5.51$ years.

The frequency of uveitis in patients with AS is lower in the study region than in most other regions. Future studies with a prospetive design, randomized patient selection, and lifelong follow up can provide a more accurate description of acute anterior uveitis in patients with AS.
\end{abstract}

Keywords: Ankylosing spondylitis, Uveitis, spondyloarthritis, prevalence

\section{Introduction}

Ankylosing Spondylitis (AS) is a chronic inflammatory rheumatic disease with a global prevalence of about $0.1 \%$ to $1.4 \%$ in the general population [1], usually affecting patients below the age of 30 [2]. The chronicity and progression of the disease significantly impair patients' function and quality of life [3]. AS mainly affects the axial skeleton, including sacroiliac joints and the spine, but $20-60 \%$ of cases may be associated with extra-articular manifestations, including peripheral arthritis, enthesis, psoriasis, inflammatory bowel disease (IBD), and acute anterior uveitis [4].

Uveitis usually presents as acute unilateral eye pain, blurred vision, and photophobia [5]. Most cases (90\%) are anterior uveitis, while posterior uveitis (a more serious problem) occurs rarely [6]. Acute anterior uveitis (AAU), more frequently diagnosed in men [7], could be the first presentation of AS and the most common extra-articular manifestation, with an estimated prevalence of $20-30 \%$ in these patients [6], 20 times greater than the general population (8.9 versus 0.42 per 1000 patient-years) [8]. As more than half of the cases diagnosed with uveitis are associated with spondyloarthritis (SpA), most commonly AS, it is important to consider and examine the possibility of SpA in any patient with uveitis [7,9]. Uveitis associated with SpA is usually unilateral and recurrent with an acute onset [5].

Notably, the activity and severity of the uveitis are associated with the degree of immune system response rather than the severity of the joint involvement, although AAU is associated with the number of joints involved in peripheral arthritis [10]. The role of immunologic function by the overexpression of interferon (IFN)- $\gamma$ and tumor necrosis factors (TNF- $\alpha$ ) suggest the inflammatory etiology of AAU and the need for innovative treatments [11, 12]. Furthermore, more than half of AAU cases and most cases of AS-associated AAU (more than 70\%) are positive for human leukocyte antigen (HLA)-B27 [13], recognized as the strongest genetic factor for AAU [14]. HLA-B27 positivity is of great clinical importance, as it has been associated with recurrent attacks, severe inflammation, and more ocular complications [15]. The disease duration and the presence of other extra-ocular diseases are associated with higher chances of the recurrence of AAU, more commonly

Personal non-commercial use only.Rheumatology Research Journal. Copyright (C) 2019. All rights reserved

*Corresponding Author: Mohammadhassan Jokar, MD; Department of Internal Medicine, Imam Reza Hospital, Mashhad, Iran, Tel/Fax: (+98) 511-8598818

Received: 01 September 2018 ; Accepted: 05 January 2019 
in the same eye [16]. In addition, AAU may be associated with ocular complications such as cataracts, glaucoma, posterior synechiae, increased intraocular pressure, and cystoid macular edema [17], some of which are reported more frequently in patients with positive HLA-B27 [18, 19]. Due to the significance of AAU and the role of HLA27 , the objective of this study was to assess the prevalence of uveitis in patients with ankylosing spondylitis.

\section{Materials and Methods}

The medical records of all patients diagnosed with AS between January $1^{\text {st }}, 2007$ and December $31^{\text {st }}, 2017$ in a rheumatology clinic in Mashhad, Iran were retrospectively studied. In this clinical study, the diagnosis of AS was made by a rheumatologist based on the modified New York criteria [20] and data recorded in the patients' medical records.

For the purpose of this study, the medical records of patients with AS who referred to this center during the study period were investigated; cases without sufficient information in their records were excluded.

Diagnostic delay was considered as the period between the patient's first spondyloarthritic symptoms [inflammatory back pain (IBP), peripheral arthritis, enthesitis and uveitis] and diagnosis of AS. Diagnoses of uveitis were made by an ophthalmologist.

The following data was collected from the patients' medical records: gender, age at symptom onset, age at diagno- sis, diagnostic delay, uveitis, and HLAB-27 status.

\section{Statistical analysis}

Statistical analysis was done with SPSS for windows software version 16 (SPSS Inc., Chicago, IL, USA). Mean values and standard deviations (SD) were used to report continuous variables, and frequency (percentage) was used for categorical/nominal variables. Student's t-test was used to compare mean values between the patients with and without AAU, and a $P$ value $<0.05$ was considered as statistically significant.

\section{Results}

The records of 317 AS patients (81.4\% male, $18.6 \%$ female with a male to female ratio $(\mathrm{M} / \mathrm{F})$ of $4.3: 1)$ were reviewed. The mean age at onset of AS was 27.01 \pm 8.63 years (minimum 12 years, maximum 55 years). The mean age at diagnosis of AS was $30.72 \pm 9.44$ years. The mean age at diagnosis of uveitis was $32.40 \pm 10.49$ years. The diagnostic delay (the interval between the onset of symptoms and diagnosis) was 3.71 years. The mean follow-up period of patients was $6.19 \pm 5.51$ years. HLA-B27 was positive in $77 \%$ of the patients $(77.3 \%$ in patients with uveitis, $76.9 \%$ in patients without uveitis, $P$ value $=0.41$ ). About $14 \%$ of patients had uveitis in the mean follow-up period of $6.19 \pm 5.51$ years. Panuveitis was present in only 2 cases.

Table 1 demonstrates the comparisons of male frequency, age at disease onset, and HLA positivity between patients with and without uveitis.

Table 1. Comparison between patients with and without uveitis

\begin{tabular}{lccc}
\hline \multicolumn{1}{c}{ Variable } & $\begin{array}{c}\text { Patients with uveitis } \\
(\mathbf{n = 4 4 )}\end{array}$ & $\begin{array}{c}\text { Patients without uveitis } \\
(\mathbf{n = 2 7 3 )}\end{array}$ & P value \\
\hline Male sex, n (\%) & $38(86.4)$ & $218(79.8)$ & 0.36 \\
Mean age at disease onset (years) & $25.47 \pm 7.29$ & $27.19 \pm 8.78$ & 0.39 \\
HLA-B27+, n (\%) & $34(77.3)$ & $210(76.9)$ & 0.41 \\
\hline
\end{tabular}

\section{Discussion}

The results of the present study indicated that a total of $14 \%$ of patients with AS developed AAU in a mean follow-up period of $6.19 \pm 5.51$ years. Although AAU is consistently the most common extra-articular manifestation of AS, different studies have reported different prevalence rates for AAU in different populations. Fallahi et al. [21] and Mitulescu [22] reported AAU in $14.1 \%$ of patients with AS, consistent with the results of the present study. Jamshidi et al. studied an Iranian population and reported that $15.3 \%$ of patients with AS had AAU [23], similar to the results of the present study. Essers et al. mentioned a prevalence of $18 \%$ for AAU in the 12-year follow up of 216 patients with AS [24]; their results are also close to the rate reported in the current study. The pooled prevalence of AAU in meta-analysis is reported to be about 20$30 \%[6,25]$. A Swedish study analyzed nationwide data from 1967-2009 and reported an AAU prevalence rate of $25.5 \%$ in patients with AS [26], a higher figure than that of the present study; this difference could be explained by the fact that they used the definition of the World Health Organization International Classification of Disease codes for diagnoses of AS [26], while that of the modified New York criteria was used in the current study. A cohort study on 504 Chinese patients with HLA-B27 positive for AAU reported 387 attacks of AAU in patients with $\mathrm{SpA}(76.8 \%)$ and 214 patients with AS (42.5\%) [27]. This rate is much higher than that found in the present study, which might be due to the fact that not all patients in the current study were 
positive for HLA-B27. A review of 126 studies concluded that the duration of AS disease had a significant effect on the prevalence of AAU and reported increased prevalence from an overall rate of $33.3 \%$ to $43 \%$ in patients with a disease duration of $>30$ years [28]. This could be one of the main reasons for the lower prevalence of AAU in the current study compared to previous ones. Hajialilo et al. reported AAU in $6.7 \%$ of patients with AS [29], which is a much lower figure than reported in the current study. They further indicated that patients with AAU had the shortest diagnosis delay. It is worth emphasizing that the significance of AAU is due not only to ophthalmologic complications, but also to its association with a more severe disease (AS), higher disease activity, and worse patient functional ability [30].

Among all patients included in the present study, 77\% were positive for HLA-B27. The positivity rate of HLA-B27 in patients with AS has been reported at $72 \%$ [13], 73\% [23], 74.8\% [31], and 76.2\% [32], which are close to that reported in the present study. These percentages are significantly higher than the rate of HLA-B27 positivity in the general population in Iran (less than 4\%) [33, 34]. HLA-B27 is the strongest genetic factor associated with AS and AAU, and a higher prevalence of AAU [28] and more severe $\mathrm{SpA}$ is observed in HLA-B27 positive patients [35]. In the present study, the frequency of AAU was $17.1 \%$ and $13.7 \%$ in HLA-B27-positive patients and HLA-B27 negative patients, respectively; no statistically significant difference was observed between the groups. Similar to the current results, some studies have suggested that AAU is not associated with HLA-B27 positivity $[31,36,37]$. Conversely, other studies have reported a significant association between HLA-B27 positivity and AAU [16]. The different results regarding the association of HLA-B27 positivity with AAU, in addition to different measurement techniques, could be explained by the fact that some HLA-B27-positive patients may be heterozygote, although most are homozygote or different subtypes of HLA-B27 [9]. Few studies comparing the characteristics of AAU between HLA-B27 positive and negative patients have ascertained the presence of a more severe disease in HLA-B27 positive cases; as reported, a higher $\mathrm{M} / \mathrm{F}$ is observed in HLA-B27 positive patients with AS-related AAU, and they are reported to have a higher recurrence rate with a higher chance of posterior synechiae, hypopyon, more fibrin and cells in the anterior chamber $[31,38,39]$. These findings emphasize the genetic role of HLA-B27 in the pathophysiology of AS and AAU, which can be used in further investigations into novel treatments.

The M/F in the current study was $4.3: 1$, which is consistent with the results of previous studies that have reported a higher frequency of AAU in male AS patients [37] with a M/F of 3.8:1 [23, 31]. In particular, HLA-B27-positive patients with AS-related AAU tend to be male $[15,31,38$, 39]. In the current study, the frequency of uveitis was also higher in males than females (14.2\% vs. $10.7 \%$ ). The finding on the mean age of patients in this study is also similar to that of previous reports, indicating AS in the young population (age $<30$ years) [23, 31]. In the current study, the mean age at onset of AS was 27.01 \pm 8.63 years, and the mean age at diagnosis was $30.72 \pm 9.44$ years. The results also showed no difference in mean age at diagnosis between patients with and without AAU, which has also been confirmed previously [37].

The diagnostic delay (the interval between the onset of symptoms and diagnosis) was 3.71 years in the present study. Some previous studies have reported a longer diagnostic delay in patients with AS: 7.88 years [21], 8 years [40], 6.9 years [41], and 9-12 years [42]. As to the evidence, the diagnostic delay is associated with higher AS severity, lower quality of life, and worse prognostic outcomes [21, $40,42]$. Therefore, paying greater attention to the symptoms associated with AS can be an effective measure for diagnosing AS earlier. As AAU is considered the most common extra-articular symptom [6], ophthalmologists can play a significant role in reducing the diagnostic delay.

The current study has some limitations. Firstly, it was a retrospective study, and data entry errors could have affected the results. Secondly, the mean follow-up period in the current study was short. Thirdly, the patients were selected from one center (although it was a tertiary medical center) and included into the study by convenient sampling method, which could limit the generalizability of the results to the whole population.

\section{Conclusion}

In conclusion, the results of the present study indicated that among 317 patients with an $\mathrm{M} / \mathrm{F}$ ratio of $4.3: 1$, the prevalence of AAU at the mean follow up of 6.2 years was $14 \%$. The prevalence of AAU in AS patients reported herein resembles that reported by other studies in the region, while it seems lower than the rates found in other regions. Furthermore, the results of this study indicated HLA-B27 positivity in $77 \%$ of patients with AS, consistent with the results of previous studies, and emphasized the role of HLA-B27 positivity in AS. Future studies with a prospective design, randomized patient selection, and a lifelong follow-up period can provide a more accurate description of AAU in patients with AS.

\section{Conflict of Interest}

The authors declare no conflicts of interest. 


\section{References}

1. Dean LE, Jones GT, MacDonald AG, Downham C, Sturrock RD, Macfarlane GJ. Global prevalence of ankylosing spondylitis. Rheumatology. 2013; 53(4):650-57. doi: 10.1093/rheumatology/ket387.

2. Poddubnyy D, Rudwaleit M. Early spondyloarthritis. Rheum Dis Clin North Am. 2012; 38(2):387-403. doi: 10.1016/j.rdc.2012.04.007.

3. Dagfinrud H, Kjeken I, Mowinckel P, Hagen KB, Kvien TK. Impact of functional impairment in ankylosing spondylitis: impairment, activity limitation, and participation restrictions. J Rheumatol. 2005; 32(3):516-23.

4. de Winter JJ, van Mens LJ, van der Heijde D, Landewe R, Baeten DL. Prevalence of peripheral and extra-articular disease in ankylosing spondylitis versus non-radiographic axial spondyloarthritis: a meta-analysis. Arthritis Res Ther. 2016; 18:196. doi: 10.1186/s13075-016-1093-z.

5. Rosenbaum JT. Uveitis in spondyloarthritis including psoriatic arthritis, ankylosing spondylitis, and inflammatory bowel disease. Clin Rheumatol. 2015; 34(6):999-1002. doi: 10.1007/s10067-015-2960-8.

6. Gouveia EB, Elmann D, Morales MSdÁ. Ankylosing spondylitis and uveitis: overview. Revista brasileira de reumatologia. 2012; 52(5):749-56. doi: 10.1590/s048250042012000500009.

7. Canouï-Poitrine F, Lekpa FK, Farrenq V, Boissinot V, Hacquard-Bouder C, Comet D. et al. Prevalence and factors associated with uveitis in spondylarthritis patients in France: results from an observational survey. Arthritis care \& research. 2012; 64(6):919-24. doi: 10.1002/acr.21616.

8. Stolwijk C, Essers I, van Tubergen A, Boonen A, Bazelier MT, De Bruin ML. et al. The epidemiology of extra-articular manifestations in ankylosing spondylitis: a population-based matched cohort study. Ann Rheum Dis. 2015; 74(7):1373-8. doi: 10.1136/annrheumdis-2014-205253.

9. Khan MA, Haroon M, Rosenbaum JT. Acute anterior uveitis and spondyloarthritis: more than meets the eye. Curr Rheumatol Rep. 2015; 17(9):59. doi: 10.1007/s11926015-0536-x.

10. Sun L, Wu R, Xue Q, Wang F, Lu P. Risk factors of uveitis in ankylosing spondylitis: an observational study. Medicine. 2016; 95(28):e4233. doi: 10.1097/ md.0000000000004233.

11. Gupta N, Agarwal A. Management of Uveitis in Spondyloarthropathy: Current Trends. Perm J. 2018; 22. doi: 10.7812/TPP/17-041.

12. Wakefield D, Chang JH, Amjadi S, Maconochie Z, Abu El-Asrar A, McCluskey P. What is new HLA-B27 acute anterior uveitis? Ocul Immunol Inflamm. 2011; 19(2):13944. doi: 10.3109/09273948.2010.542269.

13. Dumbraveanu L, Cusnir V, Groppa L, Calinina L. [HLA B 27 uveitis in ankylosing spondylitis and reactive arthritis]. Oftalmologia. 2010; 54(1):29-35.

14. Chavan H, Samant R, Deshpande A, Mankeshwar R. Correlation of HLA B27 subtypes with clinical features of ankylosing spondylitis. Int J Rheum Dis. 2011; 14(4):369-
74. doi: 10.1111/j.1756-185X.2011.01635.x.

15. Chang JH, McCluskey PJ, Wakefield D. Acute anterior uveitis and HLA-B27. Surv Ophthalmol. 2005; 50(4):36488. doi: 10.1016/j.survophthal.2005.04.003.

16. Monnet D, Breban M, Hudry C, Dougados M, Brezin AP. Ophthalmic findings and frequency of extraocular manifestations in patients with HLA-B27 uveitis: a study of 175 cases. Ophthalmology. 2004; 111(4):802-9. doi: 10.1016/j.ophtha.2003.07.011.

17. Agrawal RV, Murthy S, Sangwan V, Biswas J. Current approach in diagnosis and management of anterior uveitis. Indian J ophthalmol. 2010; 58(1):11-9. doi: 10.4103/0301-4738.58468.

18. D'Ambrosio EM, La Cava M, Tortorella P, Gharbiya M, Campanella M, Iannetti L: Clinical features and complications of the HLA-B27-associated acute anterior uveitis: a metanalysis. In: Seminars in ophthalmology: 2017: Taylor \& Francis; 2017: 689-701.

19. Yang P, Wan W, Du L, Zhou Q, Qi J, Liang L. et al. Clinical features of HLA-B27-positive acute anterior uveitis with or without ankylosing spondylitis in a Chinese cohort. Br J Ophthalmol. 2018;102(2):215-19. doi: 10.1136/ bjophthalmol-2016-309499.

20. Van Der Linden S, Valkenburg HA, Cats A. Evaluation of diagnostic criteria for ankylosing spondylitis. Arthritis Rheum. 1984; 27(4):361-68. doi: 10.1002/ art.1780270401.

21. Fallahi S, Jamshidi AR. Diagnostic Delay in Ankylosing Spondylitis: Related Factors and Prognostic Outcomes. Arch Rheumatol. 2016; 31(1):24-30. doi: 10.5606/ ArchRheumatol.2016.5562.

22. Mitulescu TC, Popescu C, Naie A, Predeteanu D, Popescu $\mathrm{V}$, Alexandrescu C. et al. Acute anterior uveitis and other extra-articular manifestations of spondyloarthritis. $\boldsymbol{J}$ Med Life. 2015; 8(3):319-25.

23. Jamshidi AR, Shahlaee A, Farhadi E, Fallahi S, Nicknam MH, Bidad $\mathrm{K}$. et al. Clinical characteristics and medical management of Iranian patients with ankylosing spondylitis. Mod Rheumatol. 2014; 24(3):499-504. doi: 10.3109/14397595.2013.844302.

24. Essers I, Ramiro S, Stolwijk C, Blaauw M, Landewe R, van der Heijde D. et al. Characteristics associated with the presence and development of extra-articular manifestations in ankylosing spondylitis: 12-year results from OASIS. Rheumatology (Oxford). 2015; 54(4):633-40. doi: 10.1093/rheumatology/keu388.

25. Stolwijk C, van Tubergen A, Castillo-Ortiz JD, Boonen A. Prevalence of extra-articular manifestations in patients with ankylosing spondylitis: a systematic review and meta-analysis. Ann Rheum Dis. 2015; 74(1):65-73. doi: 10.1136/annrheumdis-2013-203582.

26. Exarchou S, Lindstrom U, Askling J, Eriksson JK, Forsblad-d'Elia H, Neovius M. et al. The prevalence of clinically diagnosed ankylosing spondylitis and its clinical manifestations: a nationwide register study. Arthritis Res Ther. 2015; 17:118. doi: 10.1186/s13075-015-0627-0. 
27. Chung YM, Liao HT, Lin KC, Lin YC, Chou CT, Chen $\mathrm{CH}$. et al. Prevalence of spondyloarthritis in $504 \mathrm{Chi}-$ nese patients with HLA-B27-associated acute anterior uveitis. Scand J Rheumatol. 2009; 38(2):84-90. doi: $10.1080 / 03009740802385423$.

28. Zeboulon N, Dougados M, Gossec L. Prevalence and characteristics of uveitis in the spondyloarthropathies: a systematic literature review. Ann Rheum Dis. 2008; 67(7):955-59. doi: 10.1136/ard.2007.075754.

29. Hajialilo M, Ghorbanihaghjo A, Khabbazi A, Kolahi S, Rashtchizadeh N. Ankylosing spondylitis in iran; late diagnosis and its causes. Iran Red Crescent Med J. 2014; 16(4):e11798. doi: 10.5812/ircmj.11798.

30. Chen $\mathrm{CH}$, Lin KC, Chen HA, Liao HT, Liang TH, Wang HP. et al. Association of acute anterior uveitis with disease activity, functional ability and physical mobility in patients with ankylosing spondylitis: a cross-sectional study of Chinese patients in Taiwan. Clin Rheumatol. 2007; 26(6):953-7. doi: 10.1007/s10067-006-0403-2.

31. Fallahi S, Mahmoudi M, Nicknam MH, Gharibdoost F, Farhadi E, Saei A. et al. Effect of HLA-B* 27 and its subtypes on clinical manifestations and severity of ankylosing spondylitis in Iranian patients. Iran J Allergy Asthma Immunol. 2013; 12(4):321-30.

32. Nicknam MH, Mahmoudi M, Amirzargar AA, Ganjalikhani Hakemi M, Khosravi F, Jamshidi AR. et al. Determination of HLA-B27 subtypes in Iranian patients with ankylosing spondylitis. Iran J Allergy Asthma Immunol. 2008; 7(1):19-24. doi: 07.01/ijaai.1924.

33. Fouladi S, Adib M, Salehi M, Karimzadeh H, Bakhshiani $\mathrm{Z}$, Ostadi V. Distribution of HLA-B*27 alleles in patients with ankylosing spondylitis in Iran. Iran J Immunol. 2009; 6(1):49-54. doi: IJIv6i1A6.

34. Ziade NR. HLA B27 antigen in Middle Eastern and Arab countries: systematic review of the strength of association with axial spondyloarthritis and methodological gaps. BMC musculoskelet disord. 2017; 18(1):280. doi: 10.1186/s12891-017-1639-5.

35. Accorinti M, Iannetti L, Liverani M, Caggiano C, Gilardi M. Clinical features and prognosis of HLA B27-associated acute anterior uveitis in an Italian patient population. Ocul immunol inflamm. 2010; 18(2):91-96. doi: 10.3109/09273941003597268.

36. Wendling D, Prati C, Demattei C, Miceli-Richard C, Daures JP, Dougados M. Impact of uveitis on the phenotype of patients with recent inflammatory back pain: data from a prospective multicenter French cohort. Arthritis Care Res (Hoboken). 2012; 64(7):1089-93. doi: 10.1002/acr.21648.

37. Vale IMS, Pereira IA, Mastella MdS. Analysis of the frequency of uveitis in spondyloarthritis patients and associations with clinical parameters of the disease. Revista Brasileira de Oftalmologia 2018; 77(2):80-84. doi: 10.5935/0034-7280.20180017.

38. Park SC, Ham DI. Clinical features and prognosis of HLA-B27 positive and negative anterior uveitis in a Kore- an population. J Korean Med Sci 2009; 24(4):722-8. doi: 10.3346/jkms.2009.24.4.722.

39. Martin TM, Rosenbaum JT. An update on the genetics of HLA B27-associated acute anterior uveitis. Ocul immunol inflamm. 2011; 19(2):108-14. doi: 10.3109/09273948.2011.559302.

40. Seo MR, Baek HL, Yoon HH, Ryu HJ, Choi HJ, Baek HJ. et al. Delayed diagnosis is linked to worse outcomes and unfavourable treatment responses in patients with axial spondyloarthritis. Clin Rheumatol. 2015; 34(8):1397-405. doi: 10.1007/s10067-014-2768-y.

41. Aggarwal R, Malaviya AN. Diagnosis delay in patients with ankylosing spondylitis: factors and outcomes--an Indian perspective. Clin Rheumatol. 2009; 28(3):327-31. doi: 10.1007/s10067-008-1049-z.

42. Salvadorini G, Bandinelli F, Delle Sedie A, Riente L, Candelieri A, Generini S. et al. Ankylosing spondylitis: how diagnostic and therapeutic delay have changed over the last six decades. Clin Exp Rheumatol. 2012; 30(4):561-5. 
